\section{Atmospheric rooms as \\ experience in the space-time \\ in an evolutionary museum - Alexander Dorner's exhibition design}

\section{Marcelo Rafael de Carvalho Mirtes Marins de Oliveirab \\ Universidade Anhembi Morumbi}

In order to contribute to the studies of exhibition design, its practice and related fields, the aim of the article is to present and organize in a historical perspective some of the contributions and proposals made by Alexander Dorner (1893-1957), art historian, supporter of modern art. Dorner is recognized for his proposals carried out in the design of the exhibition of the rooms of the Landesmuseum in Hannover, Germany, after assuming its direction in the early 1920s. Later, he improved his conceptions when director of the Rhode Island Museum School of Design, in Providence, after immigrating to the United States in 1937.

Dorner conceptions were of a living and dynamic museum, not a dead monument in an established way, limited only to a set of exhibition rooms for historical artifacts and artistic treasures closed in shop windows, a kind of deposit of objects. His exhibitions proposals consisted in environments for the works, spaces that he called "atmospheric rooms". In these environments, the aim was to evoke the spirit of each period, in which the user, immersed, would have an opportunity to approach a visual and sensitive logic of the culture in which the works had been created.

The idea was not to create a simple imitation of the period, but to allow sensations suggested by colors and shapes, gardens, images of historical exteriors placed over windows, using of devices such as speakers and headphones (for music and poetry of the time), molding a "body imaginary" through experience.
Orcid number

In its conception, the museum should demonstrate the history of art and its aesthetic changes over time, as the artistic production of a previous time would allow the exercise of projecting the imagination in the past and updating it with the perspective of the present. This would allow the learning of history, giving more meaning to the present time and boosting and shaping the culture of the future, once the evolutionary connectivity of artistic and cultural production is understood.

In order to exhibit the artist production of his time, in partnership with the Russian artist El Lissitzky (1890-1941), he built during 1927 and 1928 what would become known as the first permanent abstract art gallery in a museum, the Abstract Cabinet (Abstraktes Kabinett). With an area smaller than twenty square meters, it had metal slats on its walls and, as visitors moved, offered a kind of optical illusion. Also sliding panels forced the public to manipulate and choose to reveal or hide certain paintings. Historical, theoretical research on exhibition design is the starting point for establishing a historical descriptive method to generate conceptual and morphological analysis parameters to characterizes an exhibition.

\section{KEYWORDS}

Exhibition design, Exhibitions history, Alexander Dorner, El Lissitzky 